\title{
Reduced circulating antioxidant defences are associated with airway hyper-responsiveness, poor control and severe disease pattern in asthma
}

\author{
Lisa G. Wood ${ }^{1,2,3 *}$ and Peter G. Gibson ${ }^{1,2,3}$ \\ ${ }^{1}$ Respiratory and Sleep Medicine, Hunter Medical Research Institute, John Hunter Hospital, Newcastle, NSW, Australia \\ ${ }^{2}$ Centre for Asthma and Respiratory Disease, University of Newcastle, Newcastle, Australia \\ ${ }^{3}$ Cooperative Research Centre for Asthma and Airways, Sydney, NSW, Australia
}

(Received 21 May 2009 - Revised 4 September 2009 - Accepted 4 September 2009 - First published online 29 October 2009)

Dietary antioxidants are important in protecting against oxidative stress. We have previously demonstrated that circulating dietary antioxidant levels are reduced in asthma. The present study examined the variation in dietary antioxidant levels in asthma, according to airway responsiveness, asthma control and clinical asthma pattern. Peripheral blood was collected from forty-one subjects with stable, persistent asthma. Airway responsiveness was assessed by hypertonic saline challenge. Asthma control was assessed using the Asthma Control Questionnaire. Clinical asthma pattern was determined using Global Initiative for Asthma (GINA) criteria. Whole-blood carotenoids ( $\beta$-carotene, lycopene, $\alpha$-carotene, $\beta$-cryptoxanthin, lutein/zeaxanthin) and tocopherols $(\alpha-, \delta$-, $\gamma$-tocopherol) were measured by HPLC. Plasma antioxidant potential (AOP) was determined by colorimetric assay (OxisResearch, Portland, OR, USA). Asthmatic subjects with airway hyper-responsiveness (AHR) had reduced levels of $\beta$-carotene and $\alpha$-tocopherol compared with those without AHR. Subjects with uncontrolled asthma had low levels of AOP compared with those with controlled or partly controlled asthma. Subjects with a severe persistent clinical asthma pattern had reduced levels of $\alpha$-tocopherol compared with those with a mild to moderate asthma pattern. We conclude that asthmatic subjects with AHR, uncontrolled asthma and a severe asthma pattern have impaired antioxidant defences and are thus most susceptible to the damaging effects of oxidative stress. This highlights the potential role for antioxidant supplementation in these subjects.

Antioxidants: Carotenoids: Tocopherols: Asthma

Oxidative stress occurs in asthma ${ }^{(1)}$ and exacerbates many detrimental features of the disease, such as airway smooth muscle contraction $^{(2)}$, airway hyper-responsiveness (AHR) ${ }^{(3)}$, epithelial shedding ${ }^{(4)}$ and vascular exudation ${ }^{(5)}$. Antioxidants play an important role in protecting against oxidative stress. Antioxidant defences include the endogenous antioxidant enzymes (superoxide dismutase, glutathione peroxidase, catalase) and exogenous antioxidants obtained from the diet, including vitamin $\mathrm{C}$, tocopherols and carotenoids.

Epidemiological evidence suggests that dietary antioxidants may be important to respiratory health. Foods rich in antioxidants, such as fresh fruit and vegetables, have been shown to be inversely associated with asthma prevalence ${ }^{(6,7)}$, wheeze ${ }^{(8,9)}$ and chronic lung disease onset ${ }^{(10)}$ and positively associated with lung function (percentage forced expiratory volume in $1 \mathrm{~s} ; \% \mathrm{FEV} 1)^{(11,12)}$. Several studies have shown a protective effect of dietary intake and/or serum levels of $\beta$-carotene $e^{(13-15)}$, lycopene $e^{(14,16)}$, lutein/zeaxanthin ${ }^{(15,17)}$, vitamin $C^{(18-20)}$, vitamin $E^{(21,22)}$ and $\alpha$-carotene ${ }^{(14)}$ on one or more respiratory endpoints.

Dietary antioxidant defences are impaired in asthma, both in the airways and systemically. This may be contributing to the expression of the disease. Airway deficiencies include vitamin $C^{(23)}$ and vitamin $E^{(23)}$ in bronchoalveolar lavage fluid. Systemic deficiencies include vitamin $\mathrm{C}$ in plasma ${ }^{(24,25)}$ and vitamin $\mathrm{E}$ in erythrocytes ${ }^{(26)}$. Se, a cofactor of glutathione peroxidase, has been shown to be reduced in asthma, with glutathione peroxidase activity also low ${ }^{(26-28)}$. We have recently shown that despite normal dietary intake, whole-blood levels of total carotenoids, lycopene, lutein, $\beta$ cryptoxanthin, $\alpha$ - and $\beta$-carotene ${ }^{(29)}$ and vitamin $\mathrm{E}^{(30)}$ are low in asthma compared with controls.

Antioxidant defences in asthma are likely to depend on individual subject characteristics. For example, subjects with severe persistent asthma have increased oxidative stress $^{(31)}$, which leads to increased utilisation of antioxidants and a possible deficit in host antioxidant defences. The aim of the present study was to investigate the variation in dietary antioxidant defences due to individual patient characteristics, including: (a) airway responsiveness; (b) level of asthma control; and (c) clinical asthma pattern.

\section{Experimental methods}

\section{Subjects}

Adults with stable persistent asthma ( $n$ 41) were recruited from the ambulatory care clinics, John Hunter Hospital.

Abbreviations: ACQ, Asthma Control Questionnaire; AHR, airway hyper-responsiveness; FEV1, forced expiratory volume in $1 \mathrm{~s}$.

* Corresponding author: Dr Lisa G. Wood, fax +612 49855850, email lisa.wood@newcastle.edu.au 
Asthma was diagnosed based upon current (past 12 months) episodic respiratory symptoms, doctor's diagnosis of asthma and AHR to hypertonic saline (ever). Asthma stability was confirmed, defined as no exacerbation, respiratory tract infection or oral corticosteroids in the past 4 weeks. Asthma control was assessed using the Asthma Control Questionnaire $(\mathrm{ACQ})^{(32)}$. 'Controlled asthma' was defined as ACQ $<0.75$. 'Partly controlled asthma' was defined as $0.75<\mathrm{ACQ}<1.5$. 'Uncontrolled asthma' was defined as ACQ $>1 \cdot 5^{(32)}$. Clinical asthma pattern was determined according to Global Initiative for Asthma (GINA) guidelines ${ }^{(33)}$. We have previously demonstrated that the relationship between asthma pattern severity and oxidative stress, measured by 8-isoprostane, is not linear, but increases exponentially with disease severity ${ }^{(31)}$. Thus for analysis, subjects with mild and moderate asthma patterns were pooled and compared with subjects with severe disease. Subjects were excluded from the study if they were current smokers or had any respiratory-related illness other than asthma on presentation. Before each visit, subjects fasted for $12 \mathrm{~h}$ and withheld short- and long-acting $\beta$-agonist medications. The present study was conducted according to the guidelines laid down in the Declaration of Helsinki and all procedures involving human subjects/patients were approved by the Hunter New England and University of Newcastle Human Research Ethics Committees. Written informed consent was obtained from all subjects/patients.

\section{Hypertonic saline challenge}

Spirometry (Minato Autospiro AS-600; Minato Medical Science, Osaka, Japan) and bronchial provocation with hypertonic saline $(4.5 \%)$ were performed as described previously $^{(34)}$. Following baseline spirometry, hypertonic saline was administered for increasing time periods $(30 \mathrm{~s}, 1 \mathrm{~min}$, $2 \mathrm{~min}, 4 \mathrm{~min}, 4 \mathrm{~min}, 4 \mathrm{~min}$ ) via an ultrasonic nebuliser (ULTRA-NEB $^{\text {тм }}$ Model 2000; De Vilbiss Healthcare Inc., Somerset, PA, USA) with a Hans Rudolph two-way valve (Hans Rudolph Inc., Shawnee, KS, USA). Spirometry was measured $1 \mathrm{~min}$ after each dose. If the FEV1 decreased by $15 \%$ from baseline, subjects were considered to be AHR. Salbutamol $(200 \mu \mathrm{g})$ was administered via a pressurised inhaler and valved holding chamber. The challenge was ceased once maximum nebulisation time was reached, when FEV1 decreased by $15 \%$ from baseline or at the subject's request. For subjects with AHR, the provocation dose required to induce a $15 \%$ fall in FEV1 from baseline (known as PD15) was calculated. The response of all subjects to hypertonic saline was also described by the dose-response slope. This is calculated by dividing the percentage fall in FEV1 from baseline by the amount of hypertonic saline inhaled $(\mathrm{ml})$.

\section{Carotenoid analysis}

HPLC methodology was used to measure whole-blood antioxidant concentrations, including carotenoids ( $\alpha$-carotene, lycopene, $\beta$-carotene, lutein/zeaxanthin and $\beta$-cryptoxanthin) and tocopherols $(\alpha-, \delta \text {-, } \gamma \text {-tocopherol })^{(29)}$. All extractions were carried out in a darkened laboratory under red light. Ethanol-ethyl acetate $(1: 1, \mathrm{v} / \mathrm{v})$ containing internal standards (canthaxanthin and butylated hydroxyanisole) was added to the sample. The solution was sonicated using a probe sonicator, centrifuged $\left(3000 \mathrm{~g}\right.$ at $4^{\circ} \mathrm{C}$ for $5 \mathrm{~min}$ ) and the supernatant fraction was collected. This process was repeated three times, adding ethyl acetate twice, then hexane to the pellet. Ultrapure water was then added to the pooled supernatant fraction and the mixture was vortexed and centrifuged. The supernatant fraction was decanted, the solvents evaporated with $\mathrm{N}_{2}$ and the sample reconstituted in dichloromethane-methanol $(1: 2$, $\mathrm{v} / \mathrm{v})$. Chromatography was performed on a Hypersil ${ }^{\mathrm{TM}}$ ODS (octadecylsilyl silica) column $(100 \mathrm{~mm} \times 2.1 \mathrm{~mm} \times 5 \mu \mathrm{m}$; Thermo Fisher Scientific Inc., Waltham, MA, USA) with a flow rate of $0.3 \mathrm{ml} / \mathrm{min}$. Analysis used a mobile phase of acetonitrile-dichloromethane-methanol $0.05 \%$ ammonium acetate (85:10:5, by vol.) and a diode array detector set at 470 and $290 \mathrm{~nm}$ for carotenoids and tocopherols, respectively.

\section{Antioxidant potential analysis}

Plasma antioxidant potential was assessed using colorimetric assay (Bioxytech AOP-490; Oxis Research, Portland, OR, USA). This assay is based upon the reduction of $\mathrm{Cu}^{2+}$ to $\mathrm{Cu}^{+}$by the combined action of all antioxidants present in the sample, using a standard of known uric acid concentration to create a calibration curve. The results of the assay are expressed as ' $\mu \mathrm{M}-\mathrm{Cu}$-reducing equivalents', based on the reduction of $2189 \mu \mathrm{M}-\mathrm{Cu}^{2+}$ to $\mathrm{Cu}^{+}$by $1 \mathrm{mM}$-uric acid.

\section{Statistical analysis}

Statistical analysis was performed using Minitab version 13.32 for Windows (Minitab, Inc., State College, PA USA). Data were tested for normality using the Anderson-Darling test.

Table 1. Subject characteristics

\begin{tabular}{|c|c|c|c|}
\hline & Mean & & SEM \\
\hline Subjects $(n)$ & & 41 & \\
\hline Male & & 27 & \\
\hline Female & & 14 & \\
\hline Age (years)* & $49 \cdot 0$ & & 3.4 \\
\hline Percentage predicted FEV1* & $80 \cdot 3$ & & 3.2 \\
\hline Percentage predicted FVC & $95 \cdot 6$ & & $2 \cdot 6$ \\
\hline Percentage FEV1/FVC* & 68.0 & & 1.4 \\
\hline \multicolumn{4}{|c|}{ Dose-response slope (\% fall $/ \mathrm{ml}) \dagger$} \\
\hline Median & & 1.37 & \\
\hline Interquartile range & & $0.36-5.59$ & \\
\hline \multicolumn{4}{|l|}{ PD15 $(\mathrm{ml})(n 24)^{\star}$} \\
\hline Geometric mean & & 0.49 & \\
\hline Log SD & & 0.52 & \\
\hline \multicolumn{4}{|c|}{ ICS ( $\mu$ g beclamethasone equivalents/d)† } \\
\hline Median & & 1000 & \\
\hline Interquartile range & & $900-2000$ & \\
\hline \multicolumn{4}{|l|}{ Atopy $(n)$} \\
\hline Yes & & 32 & \\
\hline No & & 9 & \\
\hline \multicolumn{4}{|l|}{ Asthma pattern $(n)$} \\
\hline Mild persistent & & 13 & \\
\hline Moderate persistent & & 21 & \\
\hline Severe persistent & & 7 & \\
\hline
\end{tabular}

FEV1, forced expiratory volume in 1 s; FVC, forced vital capacity; PD15, provocation dose resulting in $15 \%$ fall in baseline FEV1; ICS, inhaled corticosteroid use. * Data are normally distributed.

†Data are non-parametric. 
Data are reported as mean values with their standard errors for normal data, and medians and interquartile ranges for nonparametric data. Statistical comparisons were performed using the Student's $t$ test for normally distributed data and the Kruskal-Wallis test for non-parametric data. Associations were examined using Pearson's correlation and Spearman's rank correlation coefficients for normal and non-parametric data, respectively. All significance tests were two-sided and significance was accepted if $P<0.05$.

\section{Results}

Clinical characteristics of subjects are described in Table 1. Asthmatic subjects with AHR had reduced whole-blood levels of $\beta$-carotene, $\alpha$-tocopherol and total tocopherols, compared with those without AHR (Table 2). Subjects with uncontrolled asthma had low levels of plasma antioxidant potential compared with those with controlled or partly controlled asthma (Table 3). Subjects with a severe persistent clinical asthma pattern had reduced whole-blood levels of $\alpha$-tocopherol compared with those with a mild to moderate asthma pattern (Table 4).

To examine the importance of the various subgroups together, we used multiple linear regression models, fit to the $\log$ transformation of $\alpha$-tocopherol and $\beta$-carotene. Asthma pattern severity remained as a statistically significant predictor of $\log \alpha$-tocopherol $(P=0.045)$, adjusted for asthma control and AHR. AHR remained as a borderline statistically significant predictor of $\log \beta$-carotene $(P=0 \cdot 057)$, adjusted for asthma control and asthma pattern severity.

\section{Discussion}

Oxidative stress is an important feature of asthma pathophysiology. Impaired dietary antioxidant defences in asthma have been previously well described. The present study extends previous findings, by describing the differential nature of antioxidant deficiency in asthma. We have demonstrated a worsening of antioxidant defences in asthmatic subjects with AHR, uncontrolled asthma and a severe clinical asthma pattern.

The present study demonstrates for the first time that subjects with AHR have reduced dietary antioxidant defences, including reduced whole-blood levels of $\beta$-carotene, $\alpha$-tocopherol and total tocopherols. This suggests that these subjects also have increased oxidative stress. Oxidative stress involves production of $15-\mathrm{F}_{2 \mathrm{t}}$-isoprostane, which has been shown previously to directly induce AHR in mouse lung ${ }^{(35)}$, via thromboxane-endoperoxide receptor activation. A study by Talati et al. explored the relationship between oxidative stress, antioxidant defences and $\mathrm{AHR}^{(36)}$. This group demonstrated that $\mathrm{F}_{2}$-isoprostanes in whole lung increase following $9 \mathrm{~d}$ of daily aerosol allergen challenge. Dietary vitamin E restriction exaggerated this effect and further increased $\mathrm{F}_{2}$-isoprostanes, while supplemental vitamin $\mathrm{E}$ suppressed $\mathrm{F}_{2}$-isoprostane formation. Airway responsiveness was also

Table 2. Clinical characteristics and circulating markers of antioxidant status from subjects with asthma, by airway hyper-responsiveness

(Mean values with their standard errors or medians and interquartile ranges (IQR))

\begin{tabular}{|c|c|c|c|c|c|}
\hline & \multicolumn{2}{|c|}{ Hyper-responsive (n 24) } & \multicolumn{2}{|c|}{ Not hyper-responsive ( $n$ 17) } & \multirow[b]{2}{*}{$P$} \\
\hline & Median & IQR & Median & IQR & \\
\hline Percentage predicted FEV1* & & & & & 0.020 \\
\hline Mean & \multicolumn{2}{|c|}{73.7} & \multicolumn{2}{|c|}{89.5} & \\
\hline SEM & \multicolumn{2}{|c|}{3.4} & \multicolumn{2}{|c|}{5.4} & \\
\hline Percentage predicted FVC* & & & & & 0.139 \\
\hline Mean & \multicolumn{2}{|c|}{$92 \cdot 3$} & \multicolumn{2}{|c|}{$100 \cdot 4$} & \\
\hline SEM & \multicolumn{2}{|c|}{$3 \cdot 0$} & \multicolumn{2}{|c|}{4.5} & \\
\hline Percentage FEV1/FVC* & & & & & 0.026 \\
\hline Mean & \multicolumn{2}{|c|}{0.65} & \multicolumn{2}{|c|}{0.72} & \\
\hline SEM & \multicolumn{2}{|c|}{0.02} & \multicolumn{2}{|c|}{0.02} & \\
\hline \multicolumn{6}{|l|}{ PD15 (ml)* } \\
\hline Geometric mean & \multicolumn{2}{|c|}{0.49} & \multirow{2}{*}{\multicolumn{2}{|c|}{ NA }} & \\
\hline $\log S D$ & \multicolumn{2}{|c|}{0.52} & & & \\
\hline ICS ( $\mu \mathrm{g}$ beclamethasone equivalents/d) $\dagger$ & 1000 & $1000-2000$ & 1500 & $800-2000$ & 0.989 \\
\hline AOP ( $\mu \mathrm{M}-\mathrm{Cu}$-reducing equivalents) $†$ & 0.48 & $0.43-0.61$ & 0.46 & $0.36-0.49$ & 0.100 \\
\hline Lutein (mg/l)† & 0.108 & $0.067-0.163$ & $0 \cdot 116$ & $0.090-0.172$ & 0.354 \\
\hline$\beta$-Cryptoxanthin (mg/l)† & 0.063 & $0.039-0.093$ & 0.069 & $0.045-0.143$ & 0.272 \\
\hline Lycopene $(\mathrm{mg} / \mathrm{l}) \dagger$ & 0.115 & $0.080-0.161$ & 0.084 & $0.062-0.133$ & 0.098 \\
\hline$\alpha$-Carotene $(\mathrm{mg} / \mathrm{l}) \dagger$ & 0.010 & $0.0-0.022$ & 0.019 & $0.011-0.032$ & 0.090 \\
\hline$\beta$-Carotene $(\mathrm{mg} / \mathrm{l}) \dagger$ & 0.076 & $0.043-0.122$ & 0.128 & $0.075-0.248$ & 0.039 \\
\hline Total carotenoids $(\mathrm{mg} / \mathrm{l}) \dagger$ & 0.351 & $0.287-0.574$ & 0.459 & $0.375-0.581$ & 0.153 \\
\hline$\delta$-Tocopherol $(\mathrm{mg} / \mathrm{l}) \dagger$ & 0.185 & $0.0-0.220$ & $0 \cdot 151$ & $0.0-0.319$ & 0.500 \\
\hline$\gamma$-Tocopherol $(\mathrm{mg} / \mathrm{l}) \dagger$ & 0.152 & $0.119-0.190$ & 0.211 & $0.125-0.276$ & 0.157 \\
\hline$\alpha$-Tocopherol $(\mathrm{mg} / \mathrm{l}) \dagger$ & $3 \cdot 170$ & $2 \cdot 799-4.073$ & 4.468 & $3.365-4.916$ & 0.024 \\
\hline Total tocopherols $(\mathrm{mg} / \mathrm{l}) \dagger$ & 3.441 & $3 \cdot 210-4 \cdot 455$ & 4.923 & $3.785-5.233$ & 0.017 \\
\hline
\end{tabular}

FEV1, forced expiratory volume in 1s; FVC, forced vital capacity; PD15, provocation dose resulting in 15\% fall in baseline FEV1; NA, not applicable; ICS, inhaled corticosteroid use; AOP, antioxidant potential.

* Data are normally distributed.

†Data are non-parametric. 
Table 3. Clinical characteristics and circulating markers of antioxidant status for subjects with asthma, by asthma control

(Mean values with their standard errors or medians and interquartile ranges (IQR))

\begin{tabular}{|c|c|c|c|c|c|}
\hline & \multicolumn{2}{|c|}{$\begin{array}{l}\text { Controlled or partly } \\
\text { controlled }(n \text { 32) }\end{array}$} & \multicolumn{2}{|c|}{$\begin{array}{l}\text { Uncontrolled } \\
\qquad(n 9)\end{array}$} & \multirow[b]{2}{*}{$P$} \\
\hline & Median & IQR & Median & IQR & \\
\hline Percentage predicted FEV1* & & & & & 0.099 \\
\hline Mean & \multicolumn{2}{|c|}{83.5} & \multicolumn{2}{|c|}{$68 \cdot 8$} & \\
\hline SEM & \multicolumn{2}{|c|}{3.4} & \multicolumn{2}{|c|}{$7 \cdot 4$} & \\
\hline Percentage predicted FVC* & & & & & 0.083 \\
\hline Mean & \multicolumn{2}{|c|}{$98 \cdot 6$} & \multicolumn{2}{|c|}{$85 \cdot 3$} & \\
\hline SEM & \multirow{2}{*}{\multicolumn{2}{|c|}{$2 \cdot 6$}} & \multicolumn{2}{|c|}{6.5} & \\
\hline Percentage FEV1/FVC* & & & & & 0.340 \\
\hline Mean & \multicolumn{2}{|c|}{0.69} & \multicolumn{2}{|c|}{0.65} & \\
\hline SEM & \multicolumn{2}{|c|}{0.01} & \multicolumn{2}{|c|}{0.04} & \\
\hline PD15 (ml)* & & & & & 0.025 \\
\hline Geometric mean & \multicolumn{2}{|c|}{0.61} & \multicolumn{2}{|c|}{0.06} & \\
\hline Log SD & \multicolumn{2}{|c|}{0.12} & \multicolumn{2}{|c|}{0.16} & \\
\hline Dose-response slope $(\%$ fall $/ \mathrm{ml}) \dagger$ & $1 \cdot 26$ & $0.3-4.8$ & 7.97 & $0.9-11.4$ & 0.088 \\
\hline ICS ( $\mu \mathrm{g}$ beclamethasone equivalents/d)† & 1000 & $1000-2000$ & 1600 & $800-2200$ & 0.700 \\
\hline AOP ( $\mu \mathrm{M}-\mathrm{Cu}-$ reducing equivalents $) \dagger$ & 0.49 & $0.40-0.60$ & 0.43 & $0.41-0.46$ & 0.040 \\
\hline Lutein $(\mathrm{mg} / \mathrm{l}) \dagger$ & 0.11 & $0.08-0.16$ & 0.15 & $0.07-0.20$ & 0.313 \\
\hline$\beta$-Cryptoxanthin $(\mathrm{mg} / \mathrm{l}) \dagger$ & 0.06 & $0.04-0.11$ & 0.07 & $0.03-0.09$ & 0.508 \\
\hline Lycopene $(\mathrm{mg} / \mathrm{ll}) \dagger$ & $0 \cdot 10$ & $0.07-0.15$ & 0.08 & $0.04-0.19$ & 0.581 \\
\hline$\alpha$-Carotene $(\mathrm{mg} / \mathrm{l}) \dagger$ & 0.02 & $0.01-0.03$ & 0.01 & $0.00-0.02$ & 0.384 \\
\hline$\beta$-Carotene $(\mathrm{mg} / \mathrm{l}) \dagger$ & $0 \cdot 10$ & $0.06-0.22$ & 0.06 & $0.03-0.18$ & 0.208 \\
\hline Total carotenoids $(\mathrm{mg} / \mathrm{l}) \dagger$ & 0.41 & $0.30-0.57$ & 0.37 & $0.24-0.59$ & 0.581 \\
\hline$\delta$-Tocopherol $(\mathrm{mg} / \mathrm{l}) \dagger$ & 0.18 & $0.00-0.24$ & 0 & $0.00-0.29$ & 0.821 \\
\hline$\gamma$-Tocopherol $(\mathrm{mg} / \mathrm{l}) \dagger$ & 0.15 & $0.13-0.22$ & $0 \cdot 16$ & $0.09-0.23$ & 0.925 \\
\hline$\alpha$-Tocopherol $(\mathrm{mg} / \mathrm{l}) \dagger$ & 3.37 & $2.98-4.74$ & 4.09 & $2.90-4.56$ & 0.875 \\
\hline Total tocopherols $(\mathrm{mg} / \mathrm{l}) \dagger$ & 3.38 & $3.31-5.13$ & 4.46 & $3.18-4.98$ & 0.753 \\
\hline
\end{tabular}

FEV1, forced expiratory volume in $1 \mathrm{~s}$; FVC, forced vital capacity; PD15, provocation dose resulting in $15 \%$ fall in baseline FEV1; ICS, inhaled corticosteroid use; AOP, antioxidant potential. * Data are normally distributed.

† Data are non-parametric.

increased by vitamin E depletion and this was associated with overproduction of the bronchoalveolar lavage proteins lungkine and mammalian chitinase ${ }^{(36)}$. These proteins, which are associated with neutrophil recruitment ${ }^{(37)}$ and asthma ${ }^{(38)}$, were suggested to be contributing to the increased reactivity seen in vitamin E-restricted mice ${ }^{(36)}$. While the precise mechanisms by which antioxidants modulate AHR are unclear, subjects with reduced antioxidant defences appear more likely to have increased AHR. Indeed, in our multiple regression analysis, AHR was a borderline statistically significant predictor of $\log \beta$-carotene, adjusted for asthma control and asthma pattern severity. This also supports the hypothesis that reduced circulating levels of antioxidants are associated with airway reactivity in asthmatics. Thus antioxidant supplementation may have the potential to reduce airway responsiveness in asthma.

In the present study, we demonstrated that subjects with uncontrolled asthma have reduced dietary antioxidant defences, as they have a reduction in plasma total antioxidant potential. This is in line with our previous observation that increased levels of oxidised vitamin $\mathrm{E}$ are associated with reduced asthma control ${ }^{(30)}$. Both of these observations suggest that uncontrolled asthma is associated with oxidative stress, which leads to increased utilisation of antioxidants. A recent study, involving energy restriction, has described the association between asthma control and oxidative stress ${ }^{(39)}$. This intervention achieved striking improvements in markers of oxidative stress, including 8-isoprostane, nitrotyrosine, protein carbonyls and 4-hydroxynonenal adducts, and an improvement in antioxidant defences. This was associated with an improvement in asthma control, assessed using the $\mathrm{ACQ}^{(39)}$. In the present study, subjects with uncontrolled asthma also had more airway reactivity, demonstrated by a reduced PD15 (i.e. provocation dose resulting in $15 \%$ fall in baseline FEV1). As we have also observed that AHR is associated with reduced antioxidant defences, this may be contributing to the reduced antioxidant potential that was observed in uncontrolled asthma. Thus antioxidants may provide a means of improving asthma control.

We have demonstrated that the dietary antioxidant, $\alpha$-tocopherol, is reduced in subjects with a severe persistent asthma pattern. Furthermore, in a multiple regression model, asthma pattern severity remained as a statistically significant predictor of $\log \alpha$-tocopherol, when adjusted for asthma control and AHR. The subjects with severe asthma also had reduced lung function and more airway reactivity, demonstrated by an increase in the dose-response slope. We have previously reported that oxidative stress, measured by 8 -isoprostane, increases exponentially with disease severity ${ }^{(31)}$. Levels of oxidative stress in mild and moderate asthmatics were not significantly different to healthy controls. However, subjects with severe disease had significantly increased levels of oxidative stress. Thus subjects with severe asthma are also most likely to have a significant decrease in antioxidant levels. A previous 
Table 4. Clinical characteristics and circulating markers of antioxidant status for subjects with persistent asthma, by clinical asthma pattern

(Mean values with their standard errors or medians and interquartile ranges (IQR))

\begin{tabular}{|c|c|c|c|c|c|}
\hline & \multicolumn{2}{|c|}{ Mild-moderate $(n 34)$} & \multicolumn{2}{|c|}{ Severe $(n 7)$} & \multirow[b]{2}{*}{$P$} \\
\hline & Median & IQR & Median & IQR & \\
\hline Percentage predicted FEV1* & & & & & $<0.001$ \\
\hline Mean & \multicolumn{2}{|c|}{$85 \cdot 4$} & \multicolumn{2}{|c|}{55.4} & \\
\hline SEM & \multicolumn{2}{|c|}{$3 \cdot 1$} & \multicolumn{2}{|c|}{4.7} & \\
\hline Percentage predicted $\mathrm{FVC}^{*}$ & & & & & 0.004 \\
\hline Mean & \multicolumn{2}{|c|}{$99 \cdot 3$} & \multicolumn{2}{|c|}{77.8} & \\
\hline SEM & \multicolumn{2}{|c|}{2.5} & \multicolumn{2}{|r|}{$5 \cdot 1$} & \\
\hline Percentage FEV1/FVC* & & & & & 0.003 \\
\hline Mean & \multicolumn{2}{|c|}{0.70} & \multicolumn{2}{|r|}{0.58} & \\
\hline SEM & \multicolumn{2}{|c|}{0.01} & \multicolumn{2}{|r|}{0.03} & \\
\hline PD15 (ml)* & & & & & 0.090 \\
\hline Geometric mean & \multicolumn{2}{|c|}{0.61} & \multicolumn{2}{|r|}{0.14} & \\
\hline Log SD & \multicolumn{2}{|c|}{0.11} & \multicolumn{2}{|r|}{0.21} & \\
\hline Dose-response slope $(\%$ fall $/ \mathrm{ml}) \dagger$ & $1 \cdot 1$ & $0.3-4.4$ & $10 \cdot 9$ & $4 \cdot 3-12 \cdot 6$ & 0.006 \\
\hline ICS ( $\mu \mathrm{g}$ beclamethasone equivalents/d)† & 1000 & $800-2000$ & 1600 & $1000-2000$ & 0.805 \\
\hline AOP ( $\mu \mathrm{M}-\mathrm{Cu}$-reducing equivalents) $\dagger$ & 0.48 & $0.38-0.55$ & 0.46 & $0.42-0.48$ & 0.756 \\
\hline Lutein $(\mathrm{mg} / \mathrm{l}) \dagger$ & 0.11 & $0.08-0.17$ & $0 \cdot 11$ & $0.07-0.19$ & 0.972 \\
\hline$\beta$-Cryptoxanthin $(\mathrm{mg} / \mathrm{l}) \dagger$ & 0.07 & $0.05-0.11$ & 0.04 & $0.03-0.07$ & 0.080 \\
\hline Lycopene $(\mathrm{mg} / \mathrm{l}) \dagger$ & 0.10 & $0.07-0.14$ & 0.09 & $0.03-0.19$ & 0.862 \\
\hline$\alpha$-Carotene $(\mathrm{mg} / \mathrm{l}) \dagger$ & 0.02 & $0.01-0.02$ & 0.01 & $0.0-0.03$ & 0.676 \\
\hline$\beta$-Carotene $(\mathrm{mg} / \mathrm{l}) \dagger$ & 0.10 & $0.07-0.22$ & 0.05 & $0.03-0.14$ & $0 \cdot 111$ \\
\hline Total carotenoids $(\mathrm{mg} / \mathrm{l}) \dagger$ & 0.42 & $0.31-0.55$ & 0.32 & $0.22-0.65$ & 0.246 \\
\hline$\delta$-Tocopherol $(\mathrm{mg} / \mathrm{l}) \dagger$ & 0.19 & $0.0-0.24$ & $0 \cdot 16$ & $0.0-0.21$ & 0.477 \\
\hline$\gamma$-Tocopherol $(\mathrm{mg} / \mathrm{l}) \dagger$ & 0.17 & $0.13-0.22$ & 0.13 & $0.06-0.16$ & 0.059 \\
\hline$\alpha$-Tocopherol $(\mathrm{mg} / \mathrm{l}) \dagger$ & 4.02 & $3.03-4.80$ & $3 \cdot 15$ & $2 \cdot 27-3 \cdot 54$ & 0.035 \\
\hline Total tocopherols $(\mathrm{mg} / \mathrm{l}) \dagger$ & 4.45 & $3 \cdot 33-5 \cdot 16$ & 3.45 & $2 \cdot 38-3.98$ & 0.038 \\
\hline
\end{tabular}

study by Misso et al. demonstrated that plasma concentrations of ascorbic acid are also low in severe compared with mild to moderate asthmatics ${ }^{(25)}$. The presence of increased oxidative stress appears to deplete antioxidant defences in subjects with severe disease.

The results of antioxidant supplementation trials in asthma to date are variable. Vitamin $\mathrm{C}$ improved asthma outcomes in some trials ${ }^{(40-42)}$, but not others ${ }^{(43-45)}$. Vitamin E supplementation showed no clinical asthma benefit ${ }^{(46)}$. $\beta$-Carotene combined with vitamins $\mathrm{E}$ and $\mathrm{C}^{(47,48)}$ led to a clinical asthma improvement. Se supplementation also led to clinical improvements in asthma ${ }^{(49)}$. The heterogeneity of these results may be partly due to the use of individual nutrients. In the diet, nutrients are consumed in combination and the protective effect of antioxidants is dependent on other closely associated nutrients. Thus, dietary modifications using whole foods may be the most effective. Two recent studies have used this approach, using tomato-based, lycopene-rich supplements, and demonstrated a reduction in exercise-induced bronchoconstriction $^{(50)}$ and a reduction in airway neutrophil influx ${ }^{(51)}$. The results of the present study demonstrate that the requirement for, and potential benefit of, antioxidant supplementation may also depend on individual subject characteristics which modify the host antioxidant defences, such as the presence of AHR, the degree of asthma control and the clinical asthma pattern.

It is possible that other factors, such as dietary intake, may have contributed to the differences in antioxidant levels observed in these various asthma subgroups. While dietary intake data are not available for these subjects, we have previously shown that circulating carotenoid levels were reduced in asthma $v$. healthy controls, despite these groups having a similar dietary intake ${ }^{(29)}$. Thus, we are confident that an increased utilisation of antioxidants, in the presence of an increased oxidant burden, is an important factor contributing to the differences we have observed.

A limitation of the present study is the small number of subjects that were used and the uneven number of subjects in the subgroups studied. This can increase the likelihood of false negatives being reported, if the study is underpowered. However, the present results show that we still retained adequate power to detect some interesting and significant differences between groups. The study also tested multiple hypotheses, which can increase the likelihood of detecting a false positive result. However, the consistency in the trends that we observed gives us confidence that the statistically significant effects that we have reported are biologically important.

In conclusion, it has previously been demonstrated that dietary antioxidants are impaired in asthma. The present study extends these observations, by highlighting groups of asthma patients that are at greatest risk of oxidative damage due to impaired antioxidant defences. These include patients with AHR, uncontrolled asthma and a severe asthma pattern. Further studies using antioxidant supplementation in these subgroups of asthma patients are warranted. 


\section{Acknowledgements}

The present study was supported by the Cooperative Research Centre (CRC) for Asthma and Airways. Assistance with collection and processing of samples and collection of clinical data was received from Emma Hall, Brian Jackson, Noreen Bell, Respiratory and Sleep Medicine, Hunter Medical Research Institute, John Hunter Hospital, Newcastle, NSW, Australia.

L. G. W. coordinated the study, including preparation of the study protocol and ethics application, subject recruitment, sample collection, laboratory and data analysis and preparation of the manuscript. P. G. G. supervised the study design, collection and analysis of laboratory and clinical data and reviewed the manuscript.

The authors have no conflicts of interest.

\section{References}

1. Wood LG, Gibson PG \& Garg ML (2003) Biomarkers of lipid peroxidation, airway inflammation and asthma. Eur Respir J 21, $177-186$.

2. Rhoden KJ \& Barnes PJ (1989) Effect of hydrogen peroxide on guinea-pig tracheal muscle in vitro: role of cyclo-oxygenase and airway epithelium. Br J Pharmacol 98, 325-330.

3. Weiss EB \& Bellino JR (1986) Leukotriene-associated toxic oxygen metabolites induce airway hyperreactivity. Chest $\mathbf{8 9}$, 709-716.

4. Doelman CJA \& Bast A (1990) Oxygen radicals in lung pathology. Free Radic Biol Med 9, 381-400.

5. del Maestro RF, Bjork J \& Arfors K (1981) Increase in microvascular permeability induced by enzymatically generated free radicals. I. In vivo study. Microvasc Res 22, 239-254.

6. Shaheen SO, Sterne JAC, Thompson RL, et al. (2001) Dietary antioxidants and asthma in adults. Am J Respir Crit Care Med 164, 1823-1828.

7. La Vecchia C, Decarli A \& Pagano R (1998) Vegetable consumption and risk of chronic disease. Epidemiology 9, 208-210.

8. Butland BK, Strachan DP \& Anderson HR (1999) Fresh fruit intake and asthma symptoms in young British adults: confounding or effect modification by smoking? Eur Resp J 13, 744-750.

9. Ellwood P, Asher MI, Bjorksten B, et al. (2001) Diet and asthma, allergic rhinoconjunctivitis and atopic eczema symptom prevalence: an ecological analysis of the International Study of Asthma and Allergies in Childhood (ISAAC) data. Eur Respir J 17, 436-443.

10. Miedema I, Feskens EJM, Heederik D, et al. (1993) Dietary determinants of long-term incidence of chronic non-specific lung diseases: the Zutphen study. Am J Epidemiol 138, 37-45.

11. Cook DG, Carey IM \& Whincup PH (1997) Effect of fresh fruit consumption on lung function and wheeze in children. Thorax 52, 628-633.

12. Carey I, Strachan D \& Cook D (1998) Effects of changes in fresh fruit consumption on ventilatory function in healthy British adults. Am J Respir Crit Care Med 158, 728-733.

13. Butland BK, Fehily AM \& Elwood PC (2000) Diet, lung function and lung function decline in a cohort of 2512 middle aged men. Thorax 55, 102-108.

14. Grievink L, de Waart FG, Schouten EG, et al. (2000) Serum carotenoids, $\alpha$-tocopherol, and lung function among Dutch elderly. Am J Resp Crit Care Med 161, 790-795.

15. Schunemann HJ, Grant BJB, Freudenheim JL, et al. (2001) The relation of serum levels of antioxidant vitamins $\mathrm{C}$ and $\mathrm{E}$, retinol and carotenoids with pulmonary function in the general population. Am J Respir Crit Care Med 163, 1246-1255.
16. Ford ES, Mannino DM \& Redd SC (2004) Serum antioxidant concentrations among U.S. adults with self-reported asthma. J Asthma 41, 179-187.

17. Schunemann HJ, McCann S, Grant BJB, et al. (2002) Lung function in relation to intake of carotenoids and other antioxidant vitamins in a population-based study. Am J Epidemiol 155, 463-471.

18. Grievink L, Smit H, Ocke M, et al. (1998) Dietary intake of antioxidant (pro)-vitamins respiratory symptoms and pulmonary function: the MORGAN study. Thorax 53, 166-171.

19. Britton JR, Pavord ID \& Richards KA (1995) Dietary antioxidant vitamin intake and lung function in the general population. Am J Respir Crit Care Med 151, 1383-1387.

20. Rubin RN, Navon L \& Cassano PA (2004) Relationship of serum antioxidants to asthma prevalence in youth. Am J Respir Crit Care Med 169, 393-398.

21. Bodner C, Godden D, Brown K, et al. (1999) Antioxidant intake and adult-onset wheeze: a case-control study. Aberdeen WHEASE Study Group. Eur Respir J 13, 22-30.

22. Dow L, Tracey M, Villar A, et al. (1996) Does dietary intake of vitamins $\mathrm{C}$ and $\mathrm{E}$ influence lung function in older people? Am J Respir Crit Care Med 154, 1401-1404.

23. Kelly FJ, Mudway I, Blomberg A, et al. (1999) Altered lung antioxidant status in patients with mild asthma. Lancet 354, $482-483$.

24. Aderele WI, Ette SI, Oduwole O, et al. (1985) Plasma vitamin C (ascorbic acid) levels in asthmatic children. Afr J Med Sci 14, 115-120.

25. Misso NLA, Brooks-Wildhaber J, Ray S, et al. (2005) Plasma concentrations of dietary and nondietary antioxidants are low in severe asthma. Eur Resp J 26, 257-264.

26. Mohan IK \& Das UN (1997) Oxidant stress, antioxidants, nitric oxide and essential fatty acids in bronchial asthma. Med Sci Res 25, 307-309.

27. Powell CVE, Nash AA, Powers HJ, et al. (1994) Antioxidant status in asthma. Pediatr Pulmonol 18, 34-38.

28. Misso NLA, Powers KA, Gillon RL, et al. (1996) Reduced platelet glutathione peroxidase activity and serum selenium concentration in atopic asthmatic patients. Clin Exper Allergy 26, 838-847.

29. Wood LG, Garg ML, Blake RJ, et al. (2005) Airway and circulating levels of carotenoids in asthma and healthy controls. $J$ Am Coll Nutr 24, 448-455.

30. Wood LG, Garg ML, Blake RJ, et al. (2008) Oxidized vitamin E and glutathione as markers of clinical status in asthma. Clin Nutr 27, 579-586.

31. Wood LG, Garg ML, Simpson JL, et al. (2005) Induced sputum 8-isoprostane concentrations in inflammatory airway diseases. Am J Respir Crit Care Med 171, 426-430.

32. Juniper EF, Bousquet J, Abetz L, et al. (2006) Identifying 'well-controlled' and 'not well-controlled' asthma using the Asthma Control Questionnaire. Respir Med 100, 616-621.

33. Global Initiative for Asthma Executive and Science Committees (2008) GINA - the Global Initiative for Asthma. GINA Report, Global Strategy for Asthma Management and Prevention. http://www.ginasthma.org/guidelineitem. asp (accessed August 2008).

34. Gibson PG, Wlodarczyk J, Hensley M, et al. (1998) Epidemiological association of airway inflammation with asthma symptoms and airway hyperresponsiveness in childhood. Am J Respir Crit Care Med 158, 36-41.

35. Held HD \& Uhlig S (2000) Mechanisms of endotoxin-induced airway and pulmonary vascular hyperreactivity in mice. Am J Respir Crit Care Med 162, 1547-1552.

36. Talati M, Meyrick B, Stokes Peebles R Jr, et al. (2006) Oxidant stress modulates murine allergic airway responses. Free Radic Biol Med 40, 1210-1219. 
37. Rossi DL, Hurst SD, Xu Y, et al. (1999) Lungkine, a novel CXC chemokine, specifically expressed by lung bronchoepithelial cells. J Immunol 162, 5490-5497.

38. Zhao J, Zhu H, Wong CH, et al. (2005) Increased lungkine and chitinase levels in allergic airway inflammation: a proteomics approach. Proteomics 5, 2799-2807.

39. Johnson JB, Summer W, Cutler RG, et al. (2007) Alternate day calorie restriction improves clinical findings and reduces markers of oxidative stress and inflammation in overweight adults with moderate asthma. Free Radic Biol Med 42, 665-674.

40. Schachter EN \& Schlesinger A (1982) The attenuation of exercise-induced bronchospasm by ascorbic acid. Ann Allergy 49 , 146-151.

41. Mohsenin V, DuBois AB \& Douglas JS (1983) Effect of ascorbic acid on response to methacholine challenge in asthmatic subjects. Am Rev Resp Dis 129, 143-147.

42. Zuskin E, Lewis AJ \& Bouhuys A (1973) Inhibition of histamine-induced airway constriction by ascorbic acid. J Allergy Clin Immunol 51, 218-226.

43. Kordansky D, Rosenthal R \& Norman P (1979) The effect of vitamin A on antigen-induced bronchospasm. J Allergy Clin Immunol 63, 61-64.

44. Malo JL, Cartier A, Pineau L, et al. (1986) Lack of acute effects of ascorbic acid on spirometry and airway responsiveness to histamine in subjects with asthma. J Allergy Clin Immunol 78 $1153-1158$.

45. Ting S, Mansfield LE \& Yarbrough J (1983) Effects of ascorbic acid on pulmonary functions in mild asthma. J Asthma 20, 39.

46. Pearson PJ, Lewis SA, Britton J, et al. (2004) Vitamin E supplements in asthma: a parallel group randomised placebo controlled trial. Thorax 59, 652-656.

47. Grievink L, Jansen S, van't Veer P, et al. (1998) Acute effects of ozone on pulmonary function of cyclists receiving antioxidant supplements. Occup Environ Med 55, 13-17.

48. Romieu S, Meneses F, Ramirez M, et al. (1998) Antioxidant supplementation and respiratory functions among workers exposed to high levels of ozone. Am J Respir Crit Care Med 158, 226-232.

49. Hasselmark L, Malmgren R, Zetterstrom O, et al. (1993) Selenium supplementation in intrinsic asthma. Allergy 48, $30-36$.

50. Neuman I \& Nahum H (2000) Reduction of exercise-induced asthma oxidative stress by lycopene, a natural antioxidant. Allergy 55, 1184-1189.

51. Wood LG, Garg ML, Powell H, et al. (2008) Lycopene-rich treatments modify noneosinophilic airway inflammation in asthma: proof of concept. Free Radic Res 42, 94-102. 